\title{
Letramentos escolares em pauta: refletindo sobre um projeto que busca romper as barreiras das disciplinas
}

\author{
Claudia Maria Vasconcelos Lopes \\ UFRJ/CEFET-RJ
}

\begin{abstract}
Resumo
Em tempos de pós-modernidade, mudanças de natureza política, social, econômica e tecnológica nos proporcionam uma instrumentalização diferenciada de formas de sociabilidades e, assim, desestabilizam-se maneiras cristalizadas de ver o mundo social. Em outras palavras, busca-se a lógica da hibridade para que se entendam o mundo social e os discursos nele imbricados. Nessa desarticulação de visões arraigadas, há uma demanda da capacidade de se trabalhar interdisciplinarmente (LOPES,2007). A presente pesquisa, cuja natureza é sociointeracional (cf. VYGOTSKY 1939,1934), corrobora a ideia de que o embate entre as múltiplas linguagens e áreas deva ser ressignificado. À luz dessa perspectiva, este estudo embrionário procura analisar as barreiras encontradas por duas docentes ao elaborar um projeto que visa transpor as barreiras disciplinares. O projeto de apoio à melhoria do ensino no estado do Rio de Janeiro é fomentado pela FAPERJ. Tal discussão foca a perspectiva sócio-histórica (cf. BAKHTIN) enquanto prática social e cultural situada na contemporaneidade, convocando o olhar para a transposição de construtos teórico-metodológicos fundantes que perpassam as práticas de letramento (STREET, 1994) e a pedagogia de multiletramentos (CAZDEN, 1996). Neste viés, o diálogo entre as diferentes linguagens pode encontrar um cenário profícuo. Os dados foram gerados a partir de uma sessão reflexiva proposta pela pesquisadora para olhar as dificuldades das docentes quando idealizaram o projeto. Essa opção metodológica está fundada na concepção de pesquisa dialógica de Coulter (1999). São dados parciais, visto que a pesquisa é embrionária.
\end{abstract}

Palavras-chave: Letramentos; Interdisciplinaridade; Formação de professores

\begin{abstract}
In times of postmodernity, changes of a political, social, economic and technological nature provide us with differentiated instrumentation of sociability and thereby destabilize the crystallized ways of seeing the social world. In other words, the logic of hybridity is sought, in order to understand the social world and the discourses imbricated in it. In this disarticulation of rooted visions, there is a demand for the ability to work across disciplines (LOPES, 2007). The present research, which is of a social-interactional nature (VYGOTSKY 1939/1934), corroborates the idea that the clash between multiple languages and areas should be reframed. In light of this perspective, this embryonic study analyzes the barriers faced by two teachers in preparing a project which aimed at crossing disciplinary barriers. Both participated in the support project, which was sponsored by FAPERJ, to improve education in the state of Rio de Janeiro. This discussion focuses on the socio-historical perspective (BAKHTIN) as a
\end{abstract}


social and cultural practice situated in the contemporary world. It invites a look at the transposition of theoretical and methodological constructions based not only on literacy practices (STREET, 1994) but also on multiliteracy pedagogy (CAZDEN, 1996). This way, the dialogue among subjects can possibly find a profitable direction. The data was generated from a reflective session proposed by the researcher, to look at the difficulties of designing the project. This methodological option is based on the concept of dialogical research proposed by Coulter (1999). The data is partial, since the research is embryonic.

Keywords: Literacy, Interdisciplinarity; Teacher Education

\section{INTRODUÇÃO}

O olhar dialogizado das vozes sociais preconizado pelo círculo de Bakhtin (FARACO, 2009), assim como o de outros autores contemplados neste trabalho, convida à dinâmica do trabalho em equipe (GEE, 2000) e vai ao encontro da ideia de que, para que a aprendizagem revolucione de fato o curso do desenvolvimento (VYGOTSKY, 1939), é fundamental estabelecer "diálogos significativos entre as diferentes linguagens, de forma que os aprendizes percebam que os significados não são estáticos e nem construídos apenas no presente, em um vácuo histórico" (SZUNDY, 2014, p 22). Nessa lógica, o agir dialógico (BAKHTIN, 1920-24), quando contemplado nas práticas de letramentos, parece apontar para impactos visíveis e profícuos na esfera escolar.

Pressupondo que transpor barreiras disciplinares na arena educacional demanda práticas dialógicas, este artigo vai buscar refletir sobre as dificuldades de duas docentes em idealizar um projeto com potencial interdisciplinar. Ambas participaram do projeto PLIEP $^{1}$. Para tal, primeiramente serão abordadas algumas questões contemporâneas que ajudarão a compreender o contexto educacional atual, para em um segundo momento olhar para o modelo adequado de espaço escolar e alinhavar os pressupostos teóricos das práticas de letramento, estabelecendo em que esfera esta pesquisa se inscreve. E, ainda, convocar nos limites da próxima seção, os construtos que sustentam a ideia de que a transposição das barreiras disciplinares parece ser uma perspectiva convidativa, já que, muitas vezes nós, educadores, nos deparamos com um cenário de fato paralisante no sistema educacional brasileiro. Ao final, é possível focar na análise dos dados na

\footnotetext{
${ }^{1}$ PLIEP (Práticas de Linguagem nas Diferentes Áreas do Conhecimento na Escola Pública), coordenado pela professora Dra Paula Tatianne Carréra Szyndy na Universidade Federal do Rio de Janeiro/FAPERJ, Proc. E-26/110.115/2012. Teve seu início em abril de 2012. Disponível em http://pliep.pro.br/ último acesso em 12/08/2013
} 
perspectiva colaborativa e de intervenção na concepção dialógica de Coulter (1999). Será uma leitura parcial, por se tratar de pesquisa embrionária.

\section{QUESTÕES CONTEMPORÂNEAS: UM BREVE DESENHO}

O olhar sócio-histórico preconizado por Bakhtin/Voloshinov (1929 [1981]) vai ao encontro da discussão que defende que "o comportamento e a capacidade cognitiva de um determinado indivíduo dependerão de suas experiências, de sua história educativa, que, por sua vez, sempre terão relações com as características do grupo social e da época em que se insere"(REGO,2005,p.60). Este fato colabora para o repensar das atividades educacionais inseridas no momento contemporâneo, que devem não só estar “sempre nele situadas cultural, histórica e ideologicamente"(SZUNDY,2014, p 22), como também ser capazes de (res)significar e olhar para as questões que perpassam o dia a dia do discente que é, na maioria das vezes, nativo digital.

Segundo Gee (2000), vivenciamos a primazia da lógica econômica em relação às demais esferas sociais, propiciando uma profunda alteração nos horizontes do trabalho e da educação. Novos modelos de escola/empresa estão sendo construídos. Na ótica da customer-driven company ${ }^{2}$ privilegiam-se o trabalho em equipe, os projetos temporários, as relações horizontais, a descentralização e o indivíduo portfólio. Ainda segundo o autor, este indivíduo é mutante, capaz de modular-se conforme o interesse da empresa dentro de um sistema de servidão voluntária, que se alastra pelo espaço doméstico e o ambiente de lazer. Além disso, o que dá a um produto seu diferencial não é mais seu funcionamento ou o material do qual é feito, mas sim sua novidade; como ele é customizado, a fim de atender à identidade ou ao estilo de um determinado tipo de consumidor. Essas características refletem uma visão mercadológica do ensino que exige a flexibilidade e a prontidão do indivíduo portfólio. Ainda nesse contexto, produtos e serviços são criados, aperfeiçoados e modificados rapidamente. Gee (2000) refere-se a comunidades de prática em que cada membro coopera com sua habilidade e seus talentos, que podem ser reutilizados ou redefinidos em um outro momento. Já não é mais tão valorizado o que se sabe, mas sim o que se compartilha, a fim de agregar valor à empresa. Sendo assim, qualidades individuais não são mais privilegiadas, o

\footnotetext{
${ }^{2}$ customer-driven company- negócios que estão focados no consumidor (tradução minha)
} 
indivíduo torna-se um portfólio em constante mudança. Ele é seus projetos, e o talento individual não pode transcender ao grupo.

Coadunando com a ideia de Gee (2000), Moita Lopes (2012) afirma que o mundo está sendo mudado fundamentalmente como resultado de como as pessoas imaginam e exploram novos modos de fazer coisas novas. $\mathrm{O}$ autor refere-se às recentes ferramentas digitais e acrescenta que a cada evolução técnica uma nova etapa histórica se torna possível. Vivenciamos a exacerbação de alguns aspectos que a modernidade nos traz. Alguns deles são: sobrecarga de informações, onipresença da mídia, hiperindividualismo e abundância semiótica. Estamos atravessando a era do iphone/ipad e de uma sociedade extremamente grafocêntrica. A virada contemporânea é visível e concreta, sem deixar de mencionar a invasão das redes sociais, que parecem desestabilizar as interações humanas. Porém, a questão é como fazer coisas familiares de modos mais tecnologizados e afinados como momento contemporâneo. As instâncias educacionais parecem perceber a tecnologia como uma possível saída para a melhora no contexto escolar, mas isso gera certa inquietação entre os pesquisadores da área, como a dúvida se a função dessa agência de formação educacional seria formar usuários da tecnologia apenas como artefato. É possível afirmar que sim, pois não é difícil localizar práticas nas escolas em que os alunos são convidados apenas a pesquisar assuntos e a produzir slides concretizando o que encontraram. Essa tendência do uso da ferramenta de power point não parece ser um avanço na construção do conhecimento, à medida que esses alunos são, na maioria, nativos digitais. A problemática central seria como tirar partido do que eles já sabem fazer melhor do que nós, imigrantes digitais, e desenhar um futuro mais inovador e convidativo. Talvez seja necessário estimular os discentes a utilizar essas ferramentas para orientar suas escolhas no mundo, de forma a capacitá-los a utilizar as mídias existentes para torná-los críticos e capazes de hibridizar os gêneros, dando mais sentido às suas vidas. Moita Lopes (2005), seguindo a mesma vertente, sugere outros questionamentos: quem tem acesso a esse mundo das redes de comunicação, de novas formas de aprendizagem, de novos horizontes de significados, de redescrições da vida social, de discursos que possibilitam criticar o mundo? Ao tentar responder a tais perguntas, o que se constata é a crescente massa de refugos globais, ressaltando a convivência de altas tecnologias e pessoas fadadas ao não acesso.

Os questionamentos nesta seção tornam-se ainda mais pertinentes para nós, envolvidos com educação no Brasil. O nosso país continua na $85^{\mathrm{a}}$ posição no ranking 
mundial de $\mathrm{IDH}^{3}$. É com muita propriedade que Gee (2000, p 62) afirma que "o fracasso de minorias e crianças pobres na escola está relacionado à nossa falta de vontade ou inabilidade para dar a elas as formas de instrução que são delas por direito e que são necessárias, a fim de abrir as portas que continuam fechadas para elas”.

Vale ressaltar que, como professora de inglês no contexto da rede pública, entre questões problematizadas até então, estou eminentemente interessada e inscrita na "singularidade do meu existir-evento como professora, formadora e pesquisadora" (SZUNDY,2012, p.13 ) e em tentar, no viés dessa pesquisa, colaborar socialmente para uma prática menos excludente e que norteie não só o docente, como o discente em suas escolhas. Há que ser uma prática entendida como cultural e socialmente situada e que tenha o objetivo de promover o diálogo entre as diferentes linguagens.

\section{O espaço escolar}

Tem se tornado casa vez mais evidente a importância da educação na construção da democracia e da modernidade. Em várias partes do mundo, o tema tem ocupado papel de destaque, mobilizando a atenção não somente de pesquisadores, especialistas e responsáveis pela definição de políticas públicas, mas dos cidadãos de um modo geral. Podemos entender tal interesse como resultante das pressões impostas pelas novas e complexas demandas do mundo contemporâneo. Nesse novo cenário, a educação, particularmente aquela desenvolvida no âmbito escolar, passa a ser compreendida como um instrumento crucial para o enfrentamento dos impasses e incertezas do nosso tempo. Porém, ao observar os baixos índices de aprovação nas escolas, o alto índice de evasão e a falta de interesse dos alunos, amplamente veiculados na mídia local, é necessário aprofundar e problematizar a intricada questão. Cazden (1996) tece uma crítica à pedagogia de letramentos vigente, pois esta tradicionalmente está de acordo com a forma padrão de língua nacional. Com isso, pode-se observar que o processo de transformação e/ ou construção via escola funciona melhor para alguns. Para tornar essa situação mais paralisante, é fato que a escola dos menos abastados é carente de investimentos, o que não acontece, em geral, na escola particular. Moita Lopes (2005) ressalta que, com os avanços tecnológicos, alguns vivem mais e melhor e têm, portanto, mais oportunidades de realização. É com muita propriedade que Cope \& Kalantzis

\footnotetext{
${ }^{3}$ IDH - Índice de desenvolvimento humano. http://noticias.uol.com.br/infograficos/2013/03/14/brasilfica-na-85-posicao-no-ranking-mundial-de-idh-veja-resultado-de-todos-os-paises.htm último acesso $15 / 08 / 2013)$
} 
(2012, p. 122) argumentam que a "educação promete mudança social no jogo da mobilidade social e afirmam que a promessa de educação é universal, mas constatam que o mundo é sem dúvida desigual”.

Esses dois últimos argumentos sustentam a premissa do sistema vigente e paralisante em que apesar das desigualdades sociais, todos ainda têm a mesma chance, caso todos não alcancem o objetivo final, o sistema não pode ser culpado por tal deficiência. Finalizando o argumento, Cope e Kalantis (2012) acrescentam que a educação moderna busca assegurar a equidade; ela não pode simular produzir igualdade, mas simula a equivalência entre os grupos.

Não é nosso objetivo aprofundar essa discussão, dado o escopo reduzido do artigo, mas estas colocações são fundamentais. Ainda assim, fica latente mais um questionamento, a saber: que palco contempla e pode garantir que uma infinita diversidade de alunos aprenda de forma a participar plenamente da vida pública de forma igualitária?

Creio que respostas definitivas não encontram espaço no escopo da pesquisa; embora não possam ser engessadas ou lacradas, podem, sim, encontrar eco nos trabalhos de muitos estudiosos (Cope \& Kalantis, 2012; Moita Lopes, 2012, Cazden,1996) que defendem a ideia de que o desenvolvimento é engendrado na - e pela - prática social. Seria profícuo que a sala de aula pudesse se configurar como um espaço em que os participantes se envolvem em práticas discursivas com implicações diretas, não apenas para a construção da aprendizagem em si, mas, sobretudo, para a construção de sentidos de identidade, valor e possibilidade.

É fundamental que as práticas que circulam no cenário educacional aconteçam de novas maneiras e de diferentes perspectivas, estimulando o engajamento dos alunos de forma que os mesmos utilizem o seu conhecimento de mundo. Sob essa perspectiva, as possibilidades de expansão dos horizontes se abrem e a metáfora usada por Cope \& Kalantis (2012a) parece bastante apropriada: enquanto designers de significado ${ }^{4}$ somos também designers de futuros sociais.

Com vistas a enfatizar o que seria no e pelo espaço escolar, analiso, em seguida, o conceito de letramentos com o objetivo de dialogar com a visão de espaço escolar já anunciada, para na seção seguinte aproximar o olhar da transposição das disciplinas.

\footnotetext{
${ }^{4}$ A metáfora utilizada por Cope \& Kallantis (2012 a) quer dizer que os professores não são apenas autores de sentido, mas também de futuros sociais na sala de aula.
} 


\section{Práticas de Letramentos: reflexões para a educação}

A partir de meados dos anos 1980, a palavra letramento passou a ser usada no contexto da Educação e das Ciências Linguísticas (SOARES, 1999). Segundo Soares (1999), o que explica o surgimento dessa ideia seria a emergência de novos fatos, para compreender os fenômenos; e ela afirma ser letramento o estado ou condição que assume aquele que aprende a ler e escrever. Entretanto, essa perspectiva levou, ao longo dos anos, a uma falsa dicotomia: alfabetizado pelo método tradicional $\mathrm{x}$ letrado pelo novo método do letramento (KLEIMAN, 2010). Nesse âmbito, o conceito de letramento passou a ser usado como uma tentativa de divergir dos estudos sobre alfabetização, que destacavam competências individuais no uso e na prática da escrita. Segundo Kleiman (1995), apenas os estudos sobre alfabetização feitos por Paulo Freire eximiam-se dessa conotação.

Vale enfatizar que letramento é um conceito complexo por abarcar uma variedade de tipos de estudos em seu domínio. Há estudos que examinam o desenvolvimento social que acompanhou a expansão da escrita desde o século XVI, quando vamos encontrar a personagem Menocchio, um moleiro de Friuli perseguido pela inquisição devido às suas ideias ${ }^{5}$. Moita Lopes (2012, p 204) cita Menocchio, mostrando que este participou de comunidades de leitores ou "redes interpretativas" nas quais circulavam livros e discursos, e procura mostrar como Menochios do século XXI, “envolvidos como os chamados novos letramentos estão aprendendo a viver com modos de agir na construção de conhecimento, significados, valores e ideologias em um novo ethos $^{6}$, que diferem dos modos típicos dos letramentos tradicionais".

A questão central seria então tentar entender as consequências de diferentes práticas de letramento, socialmente determinadas, no desempenho dos sujeitos envolvidos. Para ilustrar, podemos pensar em Menocchio, ou seja, as implicações que o acesso a determinadas leituras trouxe para a vida desse herege.

Ainda em1980, a palavra letramento começou também a figurar nos estudos acadêmicos com os trabalhos de Street (1984), o que agregou extremo valor a esse campo de estudo. Com base na mesma literatura, constata-se que o letramento, mais tarde, pôde ser entendido a partir de duas vertentes: o modelo autônomo e o ideológico.

\footnotetext{
${ }^{5}$ Do livro O queijo e os vermes de Carlos Ginsburg (1987)

${ }^{6}$ Ethos - palavra de origem grega $=$ conjunto de hábitos e costumes que distinguem um poço

Ethos - modo de agir na construção de significados de acordo com Moita Lopes (2012)
} 
Este artigo se inscreve neste último, como proposto por Street, em que letramento é entendido como práticas múltiplas e plurais de uso da linguagem. Nesse mesmo cenário, em que as pesquisas na área são de interesse não só da Linguística Aplicada, mas também de outros campos, pode-se afirmar que os estudos de letramento atualmente se voltam para os que são característicos da contemporaneidade. Rojo (2010, p.436) questiona "como esboçar políticas de letramento ao longo da vida que realmente sustentem e desenvolvam os recursos, processos e metas que existem e são requeridos na vida cidadã”. Ao tentar refletir sobre esse argumento, é possível afirmar que não cabe mais à escola reproduzir modelos, e sim orientar os alunos para a criação de arenas (cf. BAKHTIN) que gerem confrontos ideológicos.

Desta forma, Cazden (1996) traz ao palco a pedagogia como design, ou seja, a pedagogia dos multiletramentos, portanto, conceitos do sistema semiótico ou design disponíveis que são mobilizados diferentemente pelos indivíduos para produzirem diferentes sentidos, dependendo de seus interesses. Multiletramentos é uma palavra escolhida para descrever dois importantes argumentos: a multiplicidade dos canais de comunicação e mídia e a crescente proeminência da diversidade cultural e linguística (CAZDEN, 1996).

Diante dessas ideias elencadas pelos educadores envolvidos no processo de construção do conhecimento e coadunando com a ideia de uma educação e formação responsável (SZUNDY, 2013), deve-se tentar compreender a influência que as questões contemporâneas têm sobre as práticas construídas na sala de aula e buscar que as mesmas propiciem reflexões críticas. É um convite à revisão das crenças docentes, com outras lentes, revendo permanentemente o que os discentes demandam e o que é possível fazer, para que não aprisionem os responsáveis pela construção, moldagem e orientação do educando. Caso contrário, é possível que o docente fique paralisado e sem estímulo. Sozinho, ele não opera mudanças no contexto escolar, é preciso muito mais. Ou seja, apoio das políticas públicas vigentes e, acima de tudo, ter uma escuta focada no contexto discente.

Parece necessário cuidado especial no uso da linguagem, que constrói os significados sobre o mundo, as pessoas e os outros; através dela, o homem age no mundo e o transforma. Nesse raciocínio, negociar a crescente variedade de linguagens e discursos (CAZDEN, 1996) parece também ser de extrema importância no âmbito da vida escolar, para que o discente desenvolva a habilidade de se engajar nos diálogos difíceis e inevitáveis à negociação da diversidade (CAZDEN, 1996). 
As colocações acima dialogam com o presente artigo, na medida em que este procura olhar um projeto que busca romper as barreiras das diferentes linguagens, numa posição de observação das crenças que estão em jogo na prática discursiva de seu cotidiano: a sala de aula. Entretanto, parece apropriado, antes de olhar os dados da sessão reflexiva e contemplá-los, refletir sobre a transposição das barreiras das disciplinas.

\section{Transpondo a barreira das disciplinas: uma breve retrospectiva, entendendo os caminhos trilhados e o futuro.}

Antes de discutir os pressupostos que sustentam a ideia de pôr em prática a integração recíproca entre várias disciplinas e campos de conhecimento, num convite para transpor as barreiras das disciplinas no contexto contemporâneo, alerto que não é objetivo deste artigo discutir esse conceito, por mais interessante e provocador que ele seja. Além disso, por si só, esse tema exigiria um fórum mais amplo. Porém, para melhor situar a formação da pesquisadora sócio-historicamente (cf. BAKHTIN), é pertinente citar que o meu interesse por essa área de estudo surgiu em 2005, quando interpelada pelo meu contexto educacional, que tinha como proposta pedagógica a fragmentação disciplinar. Foi quando percebi a necessidade de trabalhar dessa maneira, na busca de uma resposta. Na época, fui motivada pelo diálogo e pela busca pelo que seria, na realidade, trabalhar interdisciplinarmente.

Pautada ainda em pensamentos empíricos, de senso comum, mas com uma grande intuição de educação como ato responsável (SZYNDY,2013), inaugurei minhas práticas dialógicas contando apenas com meus pares mais competentes (cf VYGOTSKY) e, nesse viés, dei inicio à minha pesquisa no mestrado. Assim nasceu minha dissertação ${ }^{7}$ e um cenário mais propício e aberto à problematização do tema. Ao final da minha dissertação afirmei que toda pesquisa só tem seu começo depois do fim (AMORIM, 2001) e, como não poderia ser diferente, realizo até a presente data essa prática: pesquiso também a prática do outro para poder trabalhar com ele de forma mais competente. Sinto-me apta a, inclusive, auxiliar no processo de construção do conhecimento, no caso de professores que jamais transitaram por práticas interdisciplinares. Não são poucas as dificuldades dos docentes na busca de trilhar esse caminho dialógico (LOPES,2007).

\footnotetext{
${ }^{7}$ Episódios desafiantes enfrentados por uma professora de leitura ao preparar-se para mergulhar na interdisciplinaridade.
} 
Creio que, ao observar o outro ou até mesmo ser observada, cria-se uma atmosfera de construção dialógica do conhecimento que provoca o questionamento de validade, aplicabilidade, valor e possibilidades dessas práticas. Tais desestabilizações são profícuas e podem servir de alicerces, oferecendo condições para que nossas práticas sejam mais dialógicas, mais harmonizadas e, acima de tudo, sejam utilizadas como instrumentos que possam transformar, ao invés de manter a perspectiva disciplinar tão presente no cenário educacional brasileiro.

Foi nesse compasso que em 2011 mais uma vez fui convidada a problematizar o tema da transposição das barreiras das disciplinas. Travei diálogo com um existirevento concreto (SZUNDY, 2013), o PLIEP. Penso que os pressupostos teóricos desse projeto complementam muito positivamente a literatura na qual naveguei anteriormente, em sua maioria situada no âmbito da Educação e não da Linguística Aplicada; entretanto são concepções que dialogam. Afirmo que as intervenções deste último campo de saber geraram frutos de (des)aprendizagens e construções dialógicas fortalecendo as minhas crenças anteriores.

Creio que a ótica filosófica de Gusdorf $^{8}$ (1995), quando afirma que o conhecimento interdisciplinar deve ser uma lógica da descoberta, uma abertura recíproca, uma comunicação entre os domínios do saber, uma fecundação mútua, e não um formalismo que neutraliza todas as significações, fechando todas as saídas, por si só, não dá conta de mobilizar na sala de aula as práticas dialógicas propriamente ditas.

Penso que essa visão convida à problematização, mas ainda assim corre-se o risco de apartar a teoria da vida (SZUNDY, 2013). Parece que Gee (2000, p 44) chega mais próximo da sala de aula, quando cita o trabalho em equipe e afirma que, "nesse novo capitalismo, não é tão importante o que os indivíduos fazem sozinhos, mas o que eles podem fazer colaborativamente para adicionar valor ao negócio".

Passo na próxima seção a abordar a opção teórico-metodológica "que possibilita aos pesquisadores a construção de contextos de negociação (colaborativos), em projetos de formação contínua, com foco na compreensão e na transformação de sentidos que dão forma às escolhas diárias” (MAGALHÃES, 2011, p.15).

\footnotetext{
${ }^{8}$ GEORGES GUSDORF, nascido em 1912 perto de Bordéus, foi um filósofo e epistemólogo francês, oriundo de uma família judia originária da Alemanha. Faleceu em 17 de outubro de 2000, com 88 anos. Georges Gusdorf sofreu fortes influências de Kierkegaard e do teólogo protestante suíço Karl Barth.http://www.almedina.net/catalog/autores.php?autores id=634 acesso 26/08/2013
} 


\section{CAMINHOS METODOLÓGICOS}

A escolha teórico-metodológica desta pesquisa se inscreve na concepção dialógica de Coulter (1999), coadunando com a perspectiva de Szundy (2007), que vê o diálogo como um espaço privilegiado para a construção de conhecimento. Nesse sentido, o diálogo não é entendido como apenas um conjunto de perguntas e respostas, mas considerado na complexa dimensão dialógica Bahktiniana. Essa opção busca, dentro do contexto escolar, "criar espaços coletivos de aprendizagem e desenvolvimento na formação contínua de educadores" (MAGALHÃES, 2011, p 13) e colaborar com intervenções dentro de um contexto de negociação.

A proposta, já mencionada, é analisar as dificuldades enfrentadas no processo de tessitura de uma prática de letramento com potencial interdisciplinar, levando as docentes que a elaboram a refletir sobre suas crenças e limitações durante a construção do projeto.

Com o objetivo de melhor sistematizar e orientar o leitor, revejo a pergunta de pesquisa: até que ponto as marcas no discurso dos docentes focalizados sinalizam que foram afetados pelas experiências no PLIEP?

O instrumento utilizado será a sessão reflexiva e o objeto de análise é a materialidade linguística da sessão com a pesquisadora, que pode indicar um possível nível de dificuldade enfrentado para construir o projeto final ${ }^{9}$, à luz dos pressupostos interdisciplinares.

Parte da coleta de dados para a presente pesquisa ocorreu efetivamente em 2014, quando a pesquisadora propôs sessões reflexivas, caracterizando-se como sessões de discussão no sentido proposto por Magalhães (2011) e Szundy (2005). Foi dedicada exclusivamente a conversar sobre dificuldades enfrentadas ao elaborar o projeto solicitado ao final do projeto PLIEP.

\section{Os atores: concepções e perspectivas embrionárias}

Três docentes participaram da tessitura do projeto, porém a docente de artes não desejou participar da sessão. As outras duas envolvidas serão ficticiamente ${ }^{10}$ chamadas de Bete, docente de língua portuguesa e Paula, de geografia.

\footnotetext{
${ }^{9}$ No último módulo do PLIEP os docentes participantes foram convidados a construir um projeto interdisciplinar com foco nos pressupostos ventilados durante os encontros.

${ }^{10} \mathrm{O}$ nome das professoras foi alterado para preservar a identidade das profissionais
} 
Paula tem trinta e três anos de magistério, com licenciatura e bacharelado em geografia pela PUC/RJ e também uma complementação na universidade do Porto, em Portugal. Não deu continuidade aos seus estudos acadêmicos, no sentido de frequentar cursos de pós-graduação, como mestrado e doutorado, mas citou já ter feito parte de capacitação oferecida pelo Município do Rio de Janeiro. Em 2013 fez parte do PLIEP, mas relatou não conseguir participar efetivamente de todos os módulos. Esta dificuldade é atribuída a não liberação da mesma pela sua escola, onde a diretora não permitia que os docentes frequentassem o PLIEP, mesmo tendo sido acordada previamente a referida liberação entre os coordenadores do PLIEP e das escolas envolvidas.

Ao ser interpelada sobre o PLIEP, Paula materializou a sua opinião com o seguinte enunciado:

O PLIEP foi fantástico! As nossas diretoras atrapalharam, pois não podíamos muitas vezes participar. Momentos como aqueles deveriam ter muitas repetições até para envolver mais os professores, precisamos disso!

Fica claro que a avaliação em relação ao PLIEP é mais ampla, generalizada e positiva, apesar das dificuldades enfrentadas.

Bete é professora do ensino básico há dezoito anos, formou-se em letras clássicas com licenciatura em língua portuguesa na Universidade Federal do Rio de Janeiro. Trabalha na rede estadual, municipal e privada, concluiu o seu mestrado em Linguística Aplicada na mesma Universidade em que se licenciou em 2011 e foi uma das coordenadoras do projeto PLIEP. Atualmente é doutoranda.

Quando questionada, Bete argumentou que a academia deve se aproximar mais da escola e, por se afiliar a essa concepção, aceitou ser uma das coordenadoras do projeto PLIEP. Segundo ela o aceite ao convite demonstra a sua vontade de colaborar no viés da sua responsabilidade ética na medida em que participa da vida social e de esferas escolares cotidianamente.

Ecoando Oliveira e Szundy (2014, p. 186), Bete acrescenta que está em busca de uma formação de professores de linguagens responsiva e crítica à contemporaneidade.

Depois desse breve panorama das docentes envolvidas é necessário abordar o projeto que as mesmas construíram ao final do último módulo do projeto PLIEP.

As professoras entenderam o projeto interdisciplinar como um desafio que solicitava aos docentes que suas vozes ao longo do PLIEP se materializassem em forma de práticas de letramento que superassem as barreiras das disciplinas, elaborado em grupos de três ou mais docentes especialistas em disciplinas distintas. Voltamos o olhar, 
desta forma, para um deles, intitulado Manual de sobrevivência, elaborado por Paula e Bete.

\section{O contexto e justificativas: materializando o existir-evento}

O projeto interdisciplinar foi criado em uma Escola Municipal ${ }^{11}$ do subúrbio do Rio de Janeiro, que atende a mais de 1200 alunos, desde a Educação Infantil até o $9^{\circ}$ ano do Ensino Fundamental, situada na Ilha do Governador. Esta procura ter como prática pedagógica o incentivo a ações interdisciplinares a partir de temas como Sustentabilidade e Cidadania ${ }^{12}$. O projeto em tela, desenhado para a $6^{\mathrm{a}}$ série, propõe o diálogo de três matérias, português, artes e geografia, que elegem como eixo temático a sustentabilidade.

As docentes alegam não ter o objetivo de trazer à tona discursos prontos, compilar listas do que deve ser feito na e pela sociedade em relação ao objeto de estudo do projeto. Estas têm como meta priorizar as práticas sociais públicas sobre o referido tema e ampliá-lo com a participação dos educandos ${ }^{13}$, contemplando os usos das linguagens sobre sustentabilidade em diferentes áreas.

$\mathrm{Na}$ sequência didática ${ }^{14}$ elaborada, o projeto começa com a exibição do vídeo "Lixo Extraordinário" de VikMuniz e a professora de geografia provocando os discentes a partir dos seguintes questionamentos: O que é sustentabilidade? Como isso está (ou pode estar) presente na minha casa, na minha escola, no meu bairro? Em seguida, 20 temas são selecionados e divididos entre as duplas, de forma que estas realizem uma pesquisa orientada. Nessa etapa, a professora problematiza brevemente os temas e orienta as duplas a pesquisar e encontrar textos informativos. Em paralelo, o professor de língua portuguesa dá foco ao trabalho com gênero, começando com o gênero informativo e com a possibilidade de passagem para o instrucional, que no projeto enuncia-se como gênero textual "receita". Nesse momento as práticas de letramento se concentram nas características do gênero, procurando ir além de suas características estáveis e buscando colaborar para construção do conhecimento no viés

\footnotetext{
${ }^{11}$ Escola Municipal Rodrigo Otávio. Acesso em: <http://emrodrigootavio.blogspot.com.br/> último acesso 30 de junho de 2014

${ }^{12}$ Retirado do portal da escola: http://emrodrigootavio.blogspot.com.br/ acesso 31/08/2013

13 Um dos objetivos do projeto Acesso em: < http://www.lingnet.pro.br/moodle/course/category.php?id=23> acesso 30 de junho de2014

${ }^{14}$ As autoras do projeto apropriam-se dos pressupostos de Dolz e Schnneuwly no que tange à questão da sequência didática
} 
do trabalho com textos que circulam na esfera deste gênero, textos como "receita de pão" e "Receita de espantar tristeza" de Roseana Murray ${ }^{15}$, que são receitas em versos. Aproveitando o contexto, os alunos são convocados a trazer receitas para a sala de aula, com o intuito de serem incentivados a pesquisar em casa e depois discutir na arena educacional, especificamente língua portuguesa, como textos informativos poderiam se transformar em uma receita.

Tendo a temática do filme, lixo extraordinário, como pano de fundo, a docente de artes discute com os alunos a questão da transformação do lixo em arte e introduz a ideia de papel reciclado, fazendo referência a uma receita e tentando estabelecer uma ponte com o conteúdo que está sendo trabalhado em língua portuguesa.

O papel reciclado é produzido pelos grupos e nele serão escritas as receitas que contenham ações sustentáveis na sociedade, discutidas a partir dos temas selecionados na aula de geografia. A culminância seria que os grupos arquivassem sua produção, o papel reciclado com suas receitas, em uma cápsula do tempo que ficaria guardada na biblioteca e que apenas no $9^{\circ}$ ano poderia ser consultada, para que os alunos pudessem refletir sobre suas ações sustentáveis elaboradas três anos antes.

\section{UMA PRIMEIRA ANÁLISE DOS DADOS GERADOS}

Para auxiliar a construção do projeto interdisciplinar do último módulo, a docente responsável pelo mesmo disponibilizou uma tabela ${ }^{16}$.

Quando Paula foi questionada em relação a esta tabela, pela pesquisadora, sua fala se materializa da seguinte forma:

001 CLAUDIA No último módulo, que vocês fizeram no PLIEP , vocês receberam uma tabela para ser preenchida a partir daquele livro, que depois

003 foi adaptado por mim e pela BETE, porque a gente acreditou, pelas

004 falas que escutamos do grupo, que aquilo não estava chegando aos professores. Então nós demos uma adaptada.

005 PAULA Quando eu tentei entender, eu fui ler o que o Nilton fez, e aí eu

\footnotetext{
${ }^{15}$ Informações sobre a autora em: < http://dicasdeportugues.com/receita-de-espantar-a-tristeza > acesso: 30 de junho de 2014

${ }^{16} \mathrm{~A}$ docente responsável pelo último módulo do PLIEP postou no site do projeto: "Aqui você deverá postar seu projeto interdisciplinar PLIEP no modelo sugerido, podendo fazer as devidas adaptações. Lembre-se que um maior detalhamento, assim como exemplos de projetos interdisciplinares, você poderá encontrar em "Línguas Adicionais na escola: aprendizagens colaborativas em Inglês" de Schlatter e Garcez, livro distribuído a todos participantes do PLIEP em 2012". Disponível em: $<$ http://www.lingnet.pro.br/moodle/mod/forum/view.php?id=7378> acesso: 30 de julho de 2014
} 
006

007

008

009 entendi menos ainda...aquela tabela, que horror...que mais parecia uma camisa de força.

CLAUDIA É porque estava complicado, né?!

BETE A gente tentou adaptar (...)

$\mathrm{Na}$ linha cinco Paula se utiliza de processos mentais (tentar entender) duas vezes, chegando a se referir à tabela como um instrumento de engessamento (uma camisa de força), como pode ser observado nas linhas 006 e 007. Demonstra o seu espanto quando utiliza a palavra horror, que remete, mais uma vez, à dificuldade inicial da tessitura do projeto. Parece transmitir e reforçar a sua concepção de que a tabela dificultou e emperrou o processo de construção do projeto, quando na realidade deveria funcionar como um instrumento norteador, auxiliando o processo de construção e de (res)significação, e não algo lacrado.

É importante ressaltar que essa tabela foi apenas uma ferramenta, uma sugestão. Além disso, é válido citar que a pesquisadora menciona em seu discurso que a tabela foi adaptada (linha 009) de acordo com as demandas dos docentes participantes do PLIEP, mas Paula parece não levar esse fato em consideração. Percebo, que a adaptação feita pela docente coordenadora do projeto não foi suficiente para empoderar e validar o instrumento. A professora aparenta demonstrar uma atitude que evita o novo, próprio de quem quer fugir da (des)estabilização de algo que está cristalizado. Aponta para o desejo e a necessidade de transitar pelo que já é conhecido e estável, o desconforto de circular por esferas que propõem inovações parece a incomodar excessivamente. Entretanto, como afirma Celani (2010, p. 66), "salvo em raras exceções, o professor não quer resistir à inovação deliberadamente. Há um número grande de razões que o levam a isso", o que nos leva a procurar saber mais detalhes a respeito desse incomodo diante do desafio lançado pela professora responsável pelo módulo.

Quando interpelada, Paula tenta justificar sua insegurança com o enunciado:

010 PAULA Passar esse projeto para o papel foi uma dificuldade absurda. Ela que

011

012

013

014

015

016

017 ajudou, (apontando para Bete) porque está muito distante dos professores que estão na sala de aula. O que eu estou acostumada? Eu parto para fazer o trabalho com eles e, depois, me pedem um breve relato. E esse breve relato, que é o processo lá da escola. É uma "coisica" de nada. Então, pra colocar aí, eu tenho muita dificuldade. Se não fosse aqui a madame, ( apontando para Bete) de colocar essa forma, eu - eu ia fazer, mas ia sofrer que nem uma condenada. 
Percebe-se que as práticas na escola de Paula têm um cunho empírico e é tudo muito simples, significado ecoado em seu enunciado (me pedem um breve relato. E esse breve relato, que é o processo lá da escola, é breve mesmo. É uma "coisica" de nada).

Percebo que Paula enfatiza o breve relato apenas para mostrar que é algo rápido, não elaborado e bem raso. De certa forma, parece subestimar o valor do mesmo quando compara o que faz com o que teria que construir para o PLIEP.

A professora afirma que redigir o projeto parece ter sido uma dificuldade absurda, como pode ser constatado no excerto da linha 010, chegando a demonstrar certa tensão. Paula passa a ideia de que ela não apresenta estrutura do mundo que ela entende como sendo a linguagem acadêmica e cita o distanciamento escola/academia. Fazendo uma ponte com a fundamentação teórica já apresentada, é possível que não só há um distanciamento entre a academia e a escola, como também uma lacuna entre a escola e os discentes. Não é raro rastrear práticas de letramento que não estão em sintonia com as demandas contemporâneas citadas.

Esse mesmo fragmento apresenta verbos (passar, partir, pedir, colocar, fazer) que representam processos mais relacionados às ações físicas, exprimindo o fazer, a atitude braçal e parece não transmitir a leveza da construção que um projeto interdisciplinar pode permitir, com a oportunidade do diálogo entre matérias. Algo mecânico e não colaborativo e elástico.

Os últimos fatos não são conclusivos, na medida em que a pesquisadora não acompanhou as interações durante a construção do projeto interdisciplinar no espaço escolar. É apenas uma apreciação dos enunciados não ditos.

No fragmento abaixo Beth utiliza no seu discurso a palavra angústia (linha 027):

018 CLAUDIA BETE vamos voltar um pouco na produção desse material.

019

020

021

022

023

024

025

026

027

028

029

030

031
Você confirma isso que a PAULA colocou de que, se não fosse você, as coisas não teriam saído? Como é que foi isso?

BETH $\mathrm{Na}$ verdade, o trabalho interdisciplinar, ele é colaborativo. Acho que a principal característica é essa. No que ela sabe bem, ela vai colaborar.De fato é isso. Então quando nós tivemos essa tabela pra apresentar, era uma obrigação do curso, uma tabela que... Nosso projeto não se encaixava nessa tabela. Simplesmente isso. Houve problema no gênero. Então a PAULA ficou angustiada. Eu vi que a PAULA ficou angustiada. Eu tinha uma questão de hierarquia e poder. Eu não podia falar pra professora do módulo que isso não dava para fazer. (murmurando) Que, não abarcava. Ele não dava conta de um projeto interdisciplinar. Ele não dava conta. Então 
032

033

034

035

036 é muito mais fácil você escrever de uma maneira linear. Então a primeira angústia que a PAULA teve foi olhar isso e não conseguir encaixar. "Meu Deus, então eu não fiz interdisciplinar".Me senti uma... (risos) idiota, será que isso que eu já fiz com os alunos não é interdisciplinar?????

Bete afirma: eu vi que Paula ficou angustiada, demonstrando que percebe como Paula reage diante do desafio de não conseguir manipular a tabela. Diante da dificuldade, Paula chega a pensar na possibilidade de não ter cumprido com sua tarefa. Esse processo comportamental parece desestabilizar a docente, pois a mesma diz sentirse uma idiota. Parece apontar para a possibilidade de uma ideologia arraigada nas escolas públicas, de que o professor sem formação acadêmica em nível de mestrado/doutorado não se sente empoderado e, de certa forma, se demonstra inseguro, como pode ser constatado no seguinte excerto da linha 030 .

Fica ainda mais clara essa concepção que perpassa o discurso dos docentes que estão fora da academia, quando Paula se utiliza de um processo relacional que estabelece atributo a Bete no excerto: se não fosse a madame aqui. Segundo o dicionário Aurélio, a palavra madame é um adjetivo que significa a capacidade de exercer o poder de maneira extrema, que conserva ou carrega o poder. Essa definição parece fortalecer a tese de que Bete é quem detém o poder, pois, como já mencionado, ela é doutoranda e coordenadora do projeto, ou seja, é possível que Paula estabeleça uma relação simbólica entre os participantes do PLIEP e Bete.

Paula parece atribuir o seu possível insucesso na construção do projeto de forma colaborativa ao seu afastamento da esfera acadêmica. Porém, os dados parecem apontar para uma consciência de um inacabamento enquanto docente, e a mesma expressa o fato positivo de ter participado do PLIEP, que considera muito importante.

Como já citado, práticas dialógicas devem estar em sintonia com as demandas dos alunos. No caso desse projeto, isso foi algo bem reafirmado, a começar pelo tema escolhido, sustentabilidade. Os discentes pensaram na questão do lixo e da reciclagem, algo tão caro a nossa sociedade.

Curiosamente Bete é doutoranda, circula na esfera acadêmica, parece ser capaz de estabelecer reflexões mais complexas e indicar maturidade epistemológica, mas também demonstra sua (des)estabilização. Entretanto, a dúvida é positiva do ponto de vista da construção de conhecimento que prevê abalos deste tipo. 
Bete demonstra uma capacidade de sintetizar e compreender a dificuldade no processo de construção dos docentes e o expressa de maneira bem conceitual. Ao mesmo tempo avalia a situação e aponta a sua limitação de atuação diante da tabela sugerida pela docente responsável pelo módulo, ou seja, aparenta não sentir-se empoderada para mudar o instrumento. É válido afirmar que não era uma imposição a utilização da tabela, ficou configurado apenas como uma sugestão. Porem os dados apontam para a ideia de que as docentes compreendem que é uma imposição. É possível que as docentes observem essa tabela como uma cartilha, que não oferece espaço para negociação. No enunciado que começa na linha 028 observa-se que a docente estabelece a relação de poder entre formador e participante do curso de formação. Fica claro quando a mesma explica a dificuldade dos participantes do projeto em utilizar a tabela para auxiliar na construção do projeto.

\section{CONSIDERAÇÕES FINAIS: OS DADOS SÃO CONCLUSIVOS?}

De uma forma, mais estudos que elegem as epistemologias aqui elencadas buscam no escopo da metodologia responder às perguntas de pesquisa. Entretanto, em alguns casos, quando as respostas não são completamente compreendidas, respondidas ou são inconsistentes, estas podem servir como encaminhamentos que fomentam o fluxo contínuo das pesquisas. É visível que foi dessa forma que a leitura no capítulo anterior se configurou. É embrionário e inacabado.

Os enunciados foram mapeados e em vários momentos foram localizadas marcas que sinalizam a dificuldade dos docentes para se relacionar com o instrumento proposto pela professora do módulo final do PLIEP.

Outro fato apontado como barreira, e que responde parcialmente à pergunta, foi o fato de Paula demonstrar com clareza o seu distanciamento do discurso da academia e nesse sentido não se sentir empoderada para construir e materializar o projeto.

Neste viés, esta pesquisa dialogou com a definição da palavra madame, buscando entender o seu real valor semântico dentro do contexto em estudo, cujo docente almeja trabalhar interdisciplinarmente, mas se depara com gêneros acadêmicos que o deixa desestabilizado e congelado, apontando para um sentimento de impotência.

Porém, a pergunta não foi totalmente respondida, pois não é possível localizar no corpus da sessão reflexiva uma discussão mais profunda sobre os pressupostos que preconizam o diálogo entre as disciplinas. Percebo que, justamente pela formação 
disciplinar ser tão arraigada, é que as professoras não discutem os diálogos entre as disciplinas ou sentem-se inseguras para problematizá-lo.

É possível, que face à materialidade linguística elencada neste estudo, o último módulo seja convidado a se (res)significar, mas é prematura tal conclusão. Os dados não dão conta desta afirmação na sua plenitude, para tanto, o módulo teria que ser olhado como um todo.

As interações postadas pelos docentes na plataforma, por exemplo, teriam que fazer parte do corpus. Além disso, esse estudo não se ocupou em fazer uma crítica ao mesmo, mas sim olhar a materialidade linguística e tentar entender em que medida os docentes encontraram dificuldades para realizar a tarefa proposta.

Esta pesquisa aponta que o desafio, apesar de difícil, foi válido. Porém em função das reflexões apresentadas, é crucial, enquanto formadores e também professores inseridos neste contexto e atuando na arena educacional, acreditarmos que a formação continuada parece ser um dos únicos espaços que podem diminuir a distância visível entre a escola e a academia.

Paula aparenta esperar uma espécie de receita para se sentir estabilizada para construir o projeto. Ela demonstra claramente a necessidade de algo mais concreto que forneça informações estáveis para se sentir segura. Segundo ela, o projeto PLIEP parece não ter ofertado essa base. Acredito que a professora não tenha percebido que um dos objetivos do projeto era fazer a (des)construção de concepções fossilizadas e provocar abalos que auxiliem no processo de construção e (res)significação. Assim, espero que este estudo contribua para destacar a necessidade e fomentar a criação de arenas semelhantes ao PLIEP.

Para finalizar, é eminentemente importante ressaltar que o presente estudo insere-se no paradigma das desestabilizações e de (des)aprendizagens "que os significados novos e antigos conflitam por meio da avaliação crítica. Nesse quadro, construir confiança e confrontar ideias caminham juntos, para desafiar significados cristalizados nossos e de outros "(Magalhães, 2011, p. 36) e disto depende o diálogo professor-pesquisador.

\section{REFERÊNCIAS}

AMORIM, M. O pesquisador e o outro. Bakhtin nas ciências humanas. $2^{\mathrm{a}}$ ed.São Paulo. Editora Musa, 2001. 
BAKHTIN, M. (VOLOSHINOV, V. N.). Marxismo e filosofia da linguagem: problemas fundamentais do método sociológico na ciência da linguagem. $9^{\mathrm{a}}$ ed. São Paulo, Editora Huritec, 1981[1929].

, M..Para uma filosofia do ato responsável. Org: Augusto Ponzio e Grupo de Estudos dos Gêneros do Discurso - CEGE/UFsCar. Pedro \& João Editores.São Carlos. 2010 [1920-24].

, M. Gêneros do discurso. In BAKHTIN, M. Estética da criação verbal, $6^{\mathbf{a}}$ ed. São Paulo: Editora Martins Fontes, p.262-306, 2011 [1953].

CAZDEN, C. et al.A pedagogy of multiliteracies: Designing social futures.Harvard Educational Review.1996. Disponível em http://www.pwrfaculty.net/summerseminar/files/2011/12/new-london-multiliteracies.pdf

CELANI, M.A.A. Perguntas ainda sem respostas na formação de professores de línguas.In: GIMENEZ, T. MONTEIRO, M.C.G. (Org). Formação de professores de línguas na América Latina e transformação social. Coleção Novas Perspectivas em Linguística Aplicada. Vol. 4. Campinas, SP: Pontes Editores, p 57-67, 2010.

COPE, B. \& KALANTZIS, M. Introduction: Multiliteracies the beginnings of an idea. In Cope, B. \& Kalazantis, M. (ed) Multiliteracies, Literacy learning and the Design of Social Futures. Londres: Routledge, p. 14-24, 2012a.

. Changing the role of schools. In Cope,B. \& Kalantzis,M. Multiliteracies. Londres:Cambridge University Press. p.34-48, 2012 b.

FARACO, C.A.Linguagem \& Diálogos: as idéias lingüísticas do círculo de Bakhtin. $1^{\text {a }}$ ed.,São Paulo, Parábola Editorial, 2009.

COULTER,D.The Epic and the Novel: Dialogism and Teacher Research. 1999. Disponível em http://edr.sagepub.com/content/28/3/4

GEE, J. P..New people in new worlds: network, the new capitalism and schools.In COPE,B; KALANTZIS,M. Multiliteracies: literacy learning and the design of social futures. New York: Routledge,p. 42-68, 2000.

GINSBURG, C.O Queijo e os Vermes.3 ${ }^{a}$ ed., São Paulo: Companhia das Letras, 1987.

GUSDORF, G. Passado, Presente, Futuro da Pesquisa Interdisciplinar. Revista Tempo Brasileiro . Rio de Janeiro, abr-jun. nº 121, 1995.

KLEIMAN, A.Modelos de letramento e as práticas de alfabetização na escola.In A . Kleiman (Ed.) Os significados do letramento. Campinas, Mercado de Letras, p 22-50, 1995.

, A. Trajetórias de acesso ao mundo da escrita: relevância das práticas não escolares de letramento para o letramento escolar. (UFSC), v. 28, p. 375-400, 2010. Disponível 
http://www.periodicos.ufsc.br/index.php/perspectiva/issue/view/ISSN\%200102$\underline{5473 / \text { showToc }}$

LETRAS 2.0, 2011. PLIEP. Disponível em http://lingnet.pro.br/moodle/category.php?id=23

LOPES,C.M.V. Episódios desafiantes enfrentados por uma professora de leitura ao preparar-se para mergulhar na interdisciplinaridade. Dissertação de Mestrado, UFRJ, 2007.

MAGALHÃES, M.C.C. Pesquisa crítica de colaboração: escolhas epistemometodológicas na organização e condução de pesquisas de intervenção no contexto escola. In MAGALHÃEES, M.C.C \& FIDALGO,S. (orgs). $1^{\mathrm{a}}$ ed, Questões de Método e de linguagem na formação docente. Campinas, Mercado de Letras, p.13-40, 2011.

MOITA LOPES, L. P. Inglês no mundo contemporâneo: ampliando oportunidades sociais por meio da educação. Texto base do Simpósio da TESOL International Research Foundation (TIRF), São Paulo, 2005.

, L. P. O novo ethos dos letramentos digitais: modos de construir sentido, revolução das relações e performances identitárias fluidas. In SIGNORINI, I.FIAD, R. S. (Orgs). Ensino de língua das reformas, das inquietações e dos desafios.Belo Horizonte, Editora UFMG, p. 204-229, 2012.

REGO, T. C. Ensino e Constituição do Sujeito. Revista Viver: mente e cérebro. Coluna Memória da Pedagogia. Vygotsky: uma educação dialética. São Paulo, 2005.

ROJO, R. H. R. Letramentos escolares: coletâneas de textos nos livros didáticos de Língua Portuguesa. Perspectiva (UFSC), v. 28, p. 433-465, 2010. Disponível em http://www.periodicos.ufsc.br/index.php/perspectiva/issue/view/ISSN\%200102-

$\underline{5473 / \text { showToc }}$

SOARES, M. B..Letramento: um tema em três gêneros. $2^{\mathrm{a}}$ ed,Belo Horizonte,Editora Autêntica, 1999.

STREET, B. V. .Literacy in Theory and Practice. Inglaterra,Cambridge, CUP, 1984.

SZUNDY, P. T. C. Educação como ato responsável: a formação de professores de linguagem a luz da filosofia da linguagem do Círculo de Bakhtin. Trabalhos em Linguística Aplicada, vol $53 \mathrm{n}^{\mathrm{o}}$ 1. Campinas. Jan./Junho 2014. Disponível emhttp://www.scielo.br/scielo.php?pid=S0103-18132014000100002\&script=sci_arttext

VYGOTSKY, L. S. A Formação Social da Mente. $6^{\text {a }}$ ed. São Paulo, Martins Fontes, 1998 [1930].

\section{A AUTORA}

Claudia Maria Vasconcelos Lopes atua como professora de Inglês na rede privada e pública há 30 anos. Obteve o título de mestre em 2007 na Universidade Federal do Rio de Janeiro no programa de Linguística Aplicada e sua área de pesquisa é a transposição 
das barreiras disciplinares. Já frequentou um curso de pós-graduação Lato Sensu na Universidade Federal Fluminense na mesma área de interesse de seu mestrado. Atualmente, é professora de Inglês no ensino médio e técnico e na pós-graduação do Centro Federal de Educação Tecnológica Celso Suckow da Fonseca - CEFET/RJ Unidade Maracanã. Cursa o doutorado na Universidade Federal do Rio de Janeiro e tem como objeto de estudo repensar as fronteiras das disciplinas.

E-mail: clmlopes@uol.com.br 